\title{
Barriers and Needs for Building Integration of Solar Thermal and Photovoltaics
}

\author{
Klaudia Farkas $^{1 *}$, M.C. Munari Probst ${ }^{2}$ and Miljana Horvat ${ }^{3}$ \\ ${ }^{1}$ Dep. of Architectural Design, History and Technology, NTNU, Trondheim, Alfred Getz vei 3, NO-7491, \\ Trondheim, Norway \\ 2 EPFL ENAC IIC LESO-PB, LE 004, Station 18, CH-1015 Lausanne, Switzerland \\ ${ }^{3}$ Dep. of Architectural Science, Ryerson University, 350 Victoria St., Toronto, Ontario, M5B 2K3, Canada \\ * Corresponding Author, klaudia.farkas@ntnu.no
}

\begin{abstract}
The International Energy Agency (IEA) Task 41 is conducting an international survey concerning the integration of solar energy systems and architecture in order to identify barriers that architects are facing in incorporating active solar technologies in their design.

The survey investigates the possible barriers of solar thermal and photovoltaics, to understand why there is still a resistance among architects for using these elements in their architectural design. Moreover, it asks about the needs of architects, on what should be developed for a wider use of solar active systems in the building skin.

The survey also provides valuable information towards a comparative study of the two solar technologies from the perspective of architectural integration potentials. As the survey is conducted in 13 countries around the world (EU, Canada, South Korea), it gives a possibility to identify possible regional differences in understanding and acceptance of active solar technologies.
\end{abstract}

\section{Introduction}

\subsection{The framework of the survey, Introduction to IEA Task 41}

Despite the fact that several parts of the building skin are suitable for the integration of active solar systems, a great potential of utilizing solar energy in architecture is still unused. There are several reasons for this situation, covering economical, technological and architectural issues. The International Energy Agency launched Task 41 titled Solar Energy and Architecture that gathers researchers and practitioners to focus on the latter by developing guidelines for architects and recommendations for manufacturers to help instigate the wide spread of high quality architecture and efficient solar buildings [1].

\subsection{The survey method}

An international survey was conducted in the framework of Task 41 to identify the barriers of using active solar systems and the needs of architects for a wider use of solar energy in their architectural practice. The web-based survey was conducted internationally including 13 countries (Austria, Belgium, Canada, Denmark, France, Italy, South Korea, Norway, Portugal, Spain, Sweden and Switzerland) and was translated into 10 languages. The questions and layout of the survey was developed during the IEA Task 41 meetings with the collaboration of international participants. For each country a list of selected architects were collected. The survey was launched on the internet by 
responsible members of IEA Task41. The data was collected by the Canadian Subtask B leaders and was analyzed by an international team, who are the authors of this paper. There were 255 responses received (188 from Europe, 26 from Canada and 41 from South Korea). That is a low response rate considering the number of surveys sent out. The architects that responded to the survey are those interested in the issue and who either already have experience or are eager to integrate solar systems in their architecture. This result already shows the relatively low interest by architects towards this topic and has consequences for the conclusions drawn from the survey.

\subsection{The analysis of the survey}

The international group of IEA Task 41 defined 18 barriers and 7 strategies of solar systems' utilization in architecture based on their professional experiences. These were presented in the survey. The respondents were asked to vote for (at least) three issues they consider the most important, therefore we should have at least $255 * 3=765$ votes for both PV as barriers, ST as barriers (and also for strategies). However it seemed people voted for much more issues, in average six. It points out that many respondents couldn't limit their answers only to three. The data was collected and the issues were structured in six main categories: interest, economy, knowledge, information, products and process. Two kinds of analysis have been done. The first considers votes received for issues under one main issue (e.g.: interest, economy...etc.) and gives response rates related to the total amount of votes received from the respondents (e.g.: 1627 votes totally received for barriers of PV, among these 242 votes are for issues related to interest, that is $15 \%$ of the total amount of votes) (See Table 1.).The second considers each sub issue (e.g.: lack of interest of architects) and gives response rates related to the amount of respondents of the survey (e.g.: 255 from all countries) (See Table 2.). This analysis has been done for the total number of responses and also for each country both for PV and ST.

\section{Identifying Barriers and Strategies of Using Active Solar Systems in Architecture}

\subsection{INTEREST}

\subsubsection{Barriers}

- Lack of interest in solar design by architects and clients/developers

Solar modules are mostly considered to be technical devices, rather than building components. Therefore architects often have a resistance to use them in their design. This issue is mainly related to the lack of knowledge about the technology and available products [2]. Clients are even less familiar with these technologies, have less knowledge and motivation and consequently have less interest in implementing new technologies. However, issues like environmental awareness and long-term economic benefit can raise the interest among clients.

\subsubsection{Strategies}

The strategies for raising the interest of clients/developers and architects are mainly related to knowledge distribution and economical affordability that will be discussed later.

\subsubsection{Results of the survey}

The results of the survey showed that the lack of interest by clients/developers was one of the top issues defined as barriers in using solar energy in architecture (52,16\% for PV, $42,75 \%$ for ST.). These were valid for both PV and ST. The lack of self-interest among architects was one of the least 
important barriers $(15,69 \%$ for PV, $11,76 \%$ for ST). This may be related to the assumption, that it was mostly those architects that already are interested in the topic that filled out the survey.

\subsection{ECONOMY}

\subsubsection{Barriers}

- Not economically justifiable and lack of governmental incentives

Clients are mainly interested in investment costs. However, in the case of solar systems one should consider the costs (and incomes) also during operation, since solar modules produce energy and the initial investment costs of the material will eventually be paid back [3]. Moreover, solar components can replace other building components by their integration into the building envelope, consequently they fulfil multiple functions and relative costs become lower. Due to the higher investment costs, governmental incentives can be an important support. The two main forms are subsidies for the initial investments and feed-in-tariff systems, where the overproduction of electricity is bought by the electricity distributor.

\subsubsection{Strategies}

- Lower product prices and governmental incentives

Lower product prices are important in reducing initial investment costs. The case is much better for solar thermal systems, where the product prices are already much lower than for PV due to a more mature and simpler technology. Governmental incentives can significantly reduce the barrier of investment costs. A well-defined feed-in-tariff system can also play a role in enhancing building integration of solar energy systems. This is the case for instance in France.

\subsubsection{Results of the survey}

Issues related to economy were found to be the most important barriers in relation to PV in most countries, especially the high product prices $(75,69 \%)$. Answers related to lower product prices as strategies were similar to the answers on barriers $(79,22 \%)$. The exception was Norway $(66,67 \%)$, where the lack of interest $(88,89 \%)$ and lack of knowledge of clients $(72,22 \%)$ were the highest barriers.

The case of product prizes is different for thermal collectors on the barriers side $(35,29 \%)$. However, as strategies economic issues were as much as highlighted and top issues as in the case of photovoltaics (See Table 2.). This supports the results of a literature survey on nontechnical barriers to solar energy use which indicate that economical issues are the main forces in current society [4].

\subsection{KNOWLEDGE}

\subsubsection{Barriers}

- Lack of sufficient technical knowledge by architect, by client/developer and by consultants Solar energy systems, like other building components, require specific knowledge. Clients, architects and consultants are three different target groups, with different professional language and with different roles in the process. Consequently they require different kinds of knowledge. 
Since studies of solar energy have not been included in the general architectural education so far, therefore practicing architects need extra studies about these issues. There is resistance also as solar systems are not considered building components, but technical devices. Clients and developers should also have a basic knowledge of solar energy systems to understand the benefits of their investment. Without basic information, there is no proper confidence in these solutions, and this in turn leads to low interest. Even if the architects and clients are interested in and have sufficient knowledge on their own, they still need consultants with proper knowledge of solar systems for the realization of their projects.

\subsubsection{Strategies}

- More knowledge of the technologies by introducing specific courses about these technologies during the university studies

Education is the foundation of our future practice. Lately more and more universities have realized the importance of introducing environmental issues in architecture and launched specific courses on solar energy in architecture. Already, many workshops and special courses are organized for practitioners as well.

\subsubsection{Results of the survey}

The lack of knowledge by clients/developers was found to be the second most important barrier for ST $(42,75 \%)$ after the lack of interest of clients, and the third most important barrier for PV $(51,37 \%)$, after the two economic barriers. While in certain countries this issue was considered less important, the lack of interest of the clients (which is a step ahead of the knowledge of the clients) was found to be a top aspect among barriers. The lack of knowledge of architects was generally considered as an important barrier (40,78\% for PV, 32,94\% for ST) after the economics and issues related to clients. Especially in Germany, Italy and Switzerland, after the economic barriers, the lack of knowledge of

architects and clients are found to be the most important barriers for PV, while for solar thermal, where economic issues are not so crucial, these were the top barriers. The lack of knowledge of consultants was found to be one of the least important barriers worldwide $(24,31 \%$ for PV, $19,22 \%$ for ST).

\subsection{INFORMATION}

\subsubsection{Barriers}

- Lack of architecturally oriented literature on these technologies and useful and understandable data for architects in the standard product datasheets (e.g. mechanical strength, actual performance)

Even if university education or seminars provide some basic knowledge for architects, it is useful to have a handbook of solar systems. This should focus on issues related to architecture preferably in one's mother language so that is easy to understand and use for architects.

There is a variety of products on the market recently. However, the datasheets of these products focus mainly on engineering data, which are not very useful for architects. Architects need mainly information on energy output $/ \mathrm{m} 2$, price/m2, structural integration potentials and flexibility potentials of formal characteristics (like size, color...etc).

\subsubsection{Strategies}

- Availability of architecturally orientated information (handbooks/websites, seminars...) 
There is a number of sources that can provide useful information for architects. These are for instance accessible internet databases and handbooks, special workshops and seminars organized nationally and internationally related to this issue specially designed for architects. It is the responsibility of the "solar energy communities", like the IEA Task41 to spread this knowledge.

\subsubsection{Results of the survey}

In general, the issues above was of medium importance regarding barriers. However, in Germany for both PV (35,29\%) and ST (41,18\%) and in Switzerland for solar thermal $(44,19 \%)$ the lack of useful datasheets was found to be one of the most important barriers. Germany has a longer tradition in using solar energy systems in architecture, but the focus has mainly been on energy issues. Architects might require other types of information, however.

\subsection{PRODUCTS}

\subsubsection{Barriers}

- Lack of products suitable for quality building integration and complementary building components

In the case of thermal collectors, the current market provides a limited variety of products suitable for architectural integration, while in the case of photovoltaics a variety of products have been developed purposely for building integration. Still, in most cases aesthetical issues are not the focus of product development.

Certain surfaces are not suitable for thermal heat or electricity generation (shading, not suitable orientation...etc.) or cannot be covered with the solar products used in the building (due to different shape or size...etc.), even though the architectural concept would require the use of the same material. There is a need for complementary building components such as dummy elements. These are fake solar components, which do not produce energy, but which have the same visual appearance (colour, texture, pattern) like the solar products.

\subsubsection{Strategies}

- Availability of architecturally appealing products designed for building integration

Architects require flexibility in formal characteristics (size, shape, color...etc.) when choosing a product for their projects. Product developers should consider the needs of architects for architectural integration and to provide products with a higher flexibility of formal characteristics.

\subsubsection{Results of the survey}

The survey results showed that the main difference in perception of barriers of solar thermal and photovoltaics was product availability. For thermal collectors the lack of suitable products for architectural integration was considered the third most important barrier $(38,04 \%)$, while for photovoltaics $(33,33 \%)$ it was only the tenth. As we have already mentioned the case is better for photovoltaics, where many products have been developed for building integration. In the case of solar thermal the possibilities are more limited. Despite this difference in barriers, the availability of appealing products was found to be the third most important strategy for both technologies - after the two economic issues $(52,16 \% \mathrm{PV}, 49,02 \mathrm{ST})$. This shows that even if the variety of PV products for building integration is higher, there is still a need for development of appealing products for successful aesthetical integration [5]. 


\subsection{PROCESS}

\subsubsection{Barriers}

- Lack of tools that support design and dimensioning/sizing of the system

Architects are working with surfaces when designing the buildings with solar products. They therefore need simple tools that give data on energy output related to size and orientation.

- Technology is considered too late in the design process and insufficient time and/or resources in design process

For most architects, integrating solar products into their design is not yet a part of everyday practice. Often these technologies are considered too late in the design process, when the architectural concept already is in a developed phase and the integration of the solar components is problematic due to the potentially not suitable orientation and to the limitations in flexibility of the available solar products.

In case a technology requires a long period of pre-study that consumes a lot of time and resources, developers often prefer to skip its use. That often happens in the case of solar systems. This issue is mainly related to the lack of easily accessible information about these products.

\subsubsection{Strategies}

- Availability of simplified computer tools for architects

There are many tools for solar design. However, most of these require too detailed input and do not provide suitable information for architects. There is therefore a need for simplified computer tools that are compatible with already used architectural tools.

- Free/subsidized technical support from professional associations for the early design stage

The integration of solar systems in the early design stage is a crucial issue for a successful project. Free/subsidized technical support from professional associations would encourage the use of solar products in architecture.

\subsubsection{Results of the survey}

Issues related to the design process were found to have the fourth highest importance $(16 \%)$ as barriers after economy (21\%), knowledge (19\%) and information (18\%) related issues (See Table 1.). The survey showed similar results in the case of thermal collectors. However, the difference is much higher regarding strategies, where economic issues received almost twice as many votes $(42 \%$ for PV and $38 \%$ for ST) than ones of process (23\% for PV and $26 \%$ for ST). Still, the latter has the second highest importance both for solar thermal and photovoltaics regarding strategies.

\section{Summary and Conclusions}

\subsection{Comparing results of main categories of barriers and strategies}

The results of the survey showed that both on the barrier and strategy side and both for PV and ST, economic issues are the main driving forces (See Table 1.). However, regarding barries, knowledge of the participants and available information of solar systems were found to have similar importance, while in the case of strategies economic issues were found to have much higher (almost double for PV) 
response rates than other issues. Obviously there is a need to lower the product prices and to provide governmental incentives as a the first step for the widespread use of solar systems in architecture.

Knowledge of the participants and available information is a precondition to have an interest and to start a project, while issues related to process and products are more practical matters. It is an interesting result that theoretical issues (knowledge and available information) were more important as barriers, while the practical matters were more important as strategies. Architecture is a practical profession that requires a wide range of theoretical knowledge. However, to inspire architects, practical matters, like appealing products and technically support for design processes, should be more available.

Table. 1. Main barriers and strategies of widespread integration of PV and ST in architecture

\begin{tabular}{|c|c|c|c|}
\hline \multicolumn{2}{|c|}{ PHOTOVOLTAICS } & \multicolumn{2}{|c|}{ SOLAR THERMAL } \\
\hline BARRIERS & STRATEGIES & BARRIERS & STRATEGIES \\
\hline - Economy (21 \%) & - Economy (42 \%) & - Economy $(20 \%)$ & - Economy (38 \%) \\
\hline - Knowledge (19\%) & - Process $(23 \%)$ & - Knowledge (18\%) & - Process $(26 \%)$ \\
\hline - Information (18\%) & - Product $(16 \%)$ & - Information (18\%) & - Product (17\%) \\
\hline - Process $(16 \%)$ & - Information (13\%) & - Process $(16 \%)$ & - Information (13\%) \\
\hline - Interest (15\%) & - Knowledge (6 \%) & - Products (14\%) & - Knowledge (6 \%) \\
\hline - Products (11\%) & & - Interest (14\%) & \\
\hline
\end{tabular}

\subsection{Comparing results and strategies for the different countries}

The response rates were generally very low in most countries. It is therefore not possible to draw proper conclusions related to each country. However, a certain coherence can be observed. Firstly, where governmental subsidies or feed-in-tariff systems are well established or where the economy is strong, barriers related to knowledge and information become top issues. Secondly, in the countries that already have a tradition in using solar systems (like Germany, Switzerland, Austria), product availability and issues related to process come more into focus as strategies.

\subsection{Comparing results of detailed categories of solar thermal and photovoltaics}

Even though the main categories showed no significant difference between PV and ST, the detailed responses on strategies highlighted that in the case of solar thermal, product availability is a top issue after lack of interest and knowledge of client (See Table 2.). This is rooted in the difference between the two technologies. Photovoltaics have a higher degree of flexibility in formal characteristics (like color, shape\&size, pattern, possible translucency); moreover, their visibility has a representational role regarding environmental awareness. Since building integration came into focus, a wide range of products has been developed to suit architectural requirements. While in the case of thermal collectors, initial costs are lower, but the technology requires more bulky components and the formal potentials are limited. However, the third highest response rate for strategies was product availability both for PV $(52,16 \%)$ and for ST $(49,02 \%)$ - after the two economic strategies. This similarity indicates that there still is a need for producers of both technologies to understand architectural integration requirements. 
Table. 2. Top 3 barriers and strategies for widespread integration of PV and ST in architecture

\begin{tabular}{|c|c|}
\hline BARRIERS - PV & BARRIERS - ST \\
\hline - Not economically justifiable $(75,69 \%)$ & - Lack of interest by client $(45,10 \%)$ \\
- Lack of interest by client $(52,16 \%)$ & - Lack of knowledge by client/developer $(42,75 \%)$ \\
\hline - Lack of knowledge by client/developer $(51,37 \%)$ & - Lack of suitable products $(38,04 \%)$ \\
\hline STRATEGIES - PV & - Lower product prices $(61,96 \%)$ \\
\hline - Lower product prices $(79,22 \%)$ & - Government incentives $(50,98 \%)$ \\
- Government incentives $(58,43 \%)$ & - Availability of products $(49,02 \%)$ \\
\hline - Availability of products $(52,16 \%)$ & \\
\hline
\end{tabular}

\section{Contribution of IEA TASK 41 to remove barriers}

The IEA Task 41 focuses on architectural (aesthetic) factors that cause the limited use of solar energy in architecture. These are product availability, architectural knowledge and simple tools for the early design stage [1]. The survey showed that these factors are important issues and that there is a need for knowledge spreading and development in these fields. Workshops are organized on both national and international levels in the framework of the task. A collection of high quality architectural examples and datasheets of products are collected and will be presented on the web. Moreover, a document with guidelines for architects and a document for product developers for both technologies will be produced. For developing methods and tools a guideline will be provided, and element libraries for design tools will be developed. The aim of the group of experts in IEA Task41 is to support removing barriers highlighted in the survey.

\section{Acknowledgements}

The authors acknowledge the contribution of Miguel Amado, Carlos Barbosa, Marius Bjørge, Émilie Bouffard, Marie-Claude Dubois, Doris Ehrbar, Alain Filloux, Francesco Frontini, Shirley Gagnon, Susanne Geissler, Alessia Giovanardi, Susanne Gosztonyi, Rolf Hagen, Anne Grete Hestnes, Merete Hoff, Jun-Tae Kim, Karin Kappel, Margarethe Korolkow, Vesna Kosorić, Roberto Lollini, Marja Lundgren, Catherine Massart, Laura Maturi, Ricardo Enriquez Miranda, Kim Nagel, Suzanne Rextroth, Christian Roecker, Alessandra Scognamiglio, Maria Wall and Isa Zanetti on the survey.

\section{References}

[1] M. Wall et al, Solar Energy and Architecture, Annex Plan, IEA SHC Programme-Task 41, 2008.

[2]D. F. Montoro et al., Barriers for the introduction of Photovoltaic in the building sector, Sunrise Project, 2008

[3]D. F. Montoro et al., PV Diffusion in the Building Sector, Sunrise Project, 2008

[4]R. Margolis, J. Zuboy, Nontechnical Barriers to Solar Energy Use: Review of Recent Literature, Technical Report, NREL/TP-520-40116, Golden, Colorado, September 2006

[5]B. van Mierlo, B. Oudshoff, Literature survey and analysis of non-technical problems for the introduction of building integrated photovoltaics systems, Report IEA PVPS 7-01:1999, Amsterdam, March 1999 